Revista Destaques Acadêmicos, Lajeado, v. 13, n. 2, 2021. ISSN 2176-3070

DOI: http://dx.doi.org/10.22410/issn.2176-3070.v13i2a2021.2898

http://www.univates.br/revistas

\title{
OS PRINCÍPIOS DA CAPACIDADE CONTRIBUTIVA E DA PROGRESSIVIDADE COMO CRITÉRIO PARA UMA TRIBUTAÇÃO JUSTA
}

\author{
Tatiele Gisch Kuntz ${ }^{1}$
}

Resumo: Sendo a atividade tributária a principal fonte de arrecadação do Estado, essa deve estar alicerçada em princípios e critérios justos, de modo que nem o contribuinte seja excessivamente onerado, tão pouco o Estado deixe de se ter recursos para cumprir com suas finalidades constitucionais. Nessa perspectiva, considerou-se oportuna a elaboração de um breve estudo, com o objetivo de verificar se e, em caso positivo, como os princípios da capacidade contributiva e da progressividade podem se constituir num forte critério para uma tributação justa. Para isso, optou-se por uma abordagem qualitativa do tema. Concluiu-se que a tributação fundada em princípios próprios de uma carga tributária justa pode ser um importante instrumento na busca de uma efetiva justiça fiscal e, consequentemente, na concretização dos objetivos do próprio Estado Democrático de Direito.

Palavras-chave: Tributos. Capacidade contributiva. Progressividade. Justiça fiscal. Justiça social.

\section{INTRODUÇÃO}

A Constituição Federal de 1988 é clara ao erigir que a República Federativa do Brasil constitui-se em um Estado Democrático de Direito, bem como ao estabelecer, dentre seus objetivos fundamentais, a redução das desigualdades sociais. Assim, verifica-se que a Constituição, muito mais do que reconhecer a existência de desigualdades sociais no Brasil, impôs ao Estado o dever de atenuá-las.

É dentro dessa perspectiva que o direito tributário pode ser visto como um importante instrumento auxiliar de efetivação da justiça social, na

1 Mestre em Direito pela da Universidade de Santa Cruz do Sul -UNISC. Pós-graduada em Direito Público. Co-coordena o Projeto de Extensão Educação e Cidadania Fiscal: um instrumento de justiça e inclusão social na Univates. Advogada. Professora do curso de Direito da Universidade do Vale do Taquari- UNIVATES e da Faculdade Dom Alberto- FDA. 
medida em que as receitas obtidas, via tributação, podem ser utilizadas para concretização dos fins do Estado Democrático de Direito.

No entanto, para que isso ocorra, o Estado ao instituir ou majorar qualquer tributo deve alicerçar a sua exigência em princípios tributários, onerando com alíquotas maiores aqueles contribuintes com melhores condições e, consequentemente, com alíquotas menores aqueles que possuem menos capacidade de contribuir.

Nessa seara, o presente artigo objetiva verificar se e, em caso positivo, como os princípios da capacidade contributiva e da progressividade podem se constituir num forte critério para uma tributação justa.

Diante desse cenário, o presente estudo se justifica em razão da importância de se estabelecer, no Brasil, uma tributação que esteja, de fato, alicerçada em princípios e, em decorrência disso, seja exigida de forma justa dos contribuintes. Não obstante isso, a análise se justifica, também, diante das desigualdades sociais existentes, as quais podem ser minimizadas ao se assegurar uma carga tributária que seja adequada à efetiva capacidade contributiva dos cidadãos.

Nessa conjuntura, procura-se responder a seguinte indagação: Os princípios da capacidade contributiva e da progressividade podem ser considerados como critérios para uma tributação justa?

Para exame do proposto, realizou-se um estudo de cunho qualitativo visando a interpretação e analise dos dados por meio da pesquisa bibliográfica. Utilizou-se, ainda, o método dedutivo, o qual parte de argumentos gerais para particulares.

Assim, a reflexão que segue, no primeiro momento, trata da importância da tributação para um Estado Democrático de Direito. Após, passa-se a discorrer acercar dos princípios da capacidade contributiva e da progressividade. Por fim, faz-se uma breve explanação acerca de como os princípios da capacidade contributiva e da progressividade podem ser critérios para um sistema tributário mais justo.

\section{A IMPORTÂNCIA DA TRIBUTAÇÃO NO ESTADO DEMOCRÁTICO DE DIREITO}

A Constituição Federal de 1988 enumera, em seu artigo primeiro, como fundamentos da República Federativa do Brasil, a soberania; a cidadania; a dignidade da pessoa humana; os valores sociais do trabalho e da livre iniciativa e o pluralismo político. Do mesmo modo, estabelece que a República Federativa do Brasil, formada pela união indissolúvel dos Estados, Municípios e Distrito Federal, constitui-se em um Estado Democrático de Direito (BRASIL, 1988).

Para Bolzan de Morais (2000, p. 82), o Estado Democrático de Direito, instituído pela Carta de 1988, é uma espécie de evolução dos modelos estatais 
até então conhecidos, porquanto "emerge como um aprofundamento da fórmula, de um lado, do Estado de Direito e, de outro, do Walfare State", possuindo como uma de suas principais características a atuação do cidadão na administração pública.

No mesmo sentido, são os ensinamentos de Nogueira (2003, p. 246) para quem o Estado Democrático de Direito "surge como a modalidade mais avançada do chamado Estado de Direito, incorporando conteúdos da etapa anterior [...] e fazendo recair a tônica sobre o aspecto da participação dos cidadãos na realização de seus fins".

Nessa linha, pode-se entender que "a base do conceito de Estado Democrático de Direito é, sem dúvida, a noção de governo do povo, revelada pela própria etimologia do termo democracia [...]" (DALLARI, 2001, p. 145).

Ainda, segundo os ensinamentos de Canotilho (2002, p.100) é o princípio da soberania popular que "serve de "charneira" entre o "Estado de direito" e o "Estado democrático" possibilitando a compreensão da moderna fórmula Estado de direito democrático".

Nessa perspectiva, sendo o Estado Constitucional estruturado como um Estado Democrático de Direito, "confirma-se este como uma ordem de domínio de legitimidade pelo povo, devendo o poder do Estado se organizar e ser exercido em termos democráticos" (BUFFON; MATOS, 2015, p. 52).

A respeito do tema, Canotilho (2002, p. 100) leciona que o "Estado Constitucional é mais do que Estado de direito", já que o elemento democrático "não foi apenas introduzido para "travar" o poder (to check the Power); foi também reclamado pela necessidade de legitimação do mesmo poder (to legitimize State Power)".

Portanto, pode-se compreender que a noção de Estado Democrático de Direito deriva da legitimação do exercício do poder político e está, indissociavelmente, ligada à efetivação dos direitos fundamentais (STRECK, 2002).

Contudo, para que o Estado de Direito Democrático possa assegurar o exercício de direitos sociais e individuais, a liberdade, a segurança, o bem-estar, o desenvolvimento, a igualdade e a justiça, conforme estabelece o preâmbulo da Constituição Federal, faz-se imprescindível a obtenção de recursos financeiros que possam custear as suas atividades.

Isso porque, "os fins e objetivos políticos e econômicos do Estado só podem ser financiados pelos ingressos nas receitas públicas", que possui na arrecadação de tributos sua principal fonte (TORRES, 2011, p. 3).

De tal modo, pode-se compreender que a Constituição, ao passo que assegura direitos fundamentais, também, impõe deveres aos cidadãos, dentre dos quais se destaca o dever de pagar tributos. 
A respeito da relação existente entre direitos e deveres, Nabais (2004, p. 40) esclarece que esses se constituem em "[...] uma categoria constitucional própria, expressão imediata ou directa de valores e interesses comunitários diferentes e contrapostos aos valores e interesses individuais consubstanciados na figura dos direitos fundamentais".

Nessa perspectiva, percebe-se que os direitos e os deveres fundamentais possuem uma relação de conexão funcional, pois para que o Estado possa assegurar direitos, faz-se necessária a imposição de deveres e responsabilidades aos cidadãos.

Nas palavras de Buffon e Matos (2015, p. 142) "sem a arrecadação de recursos, não há como realizar políticas públicas que sirvam à concretização das promessas constitucionais, nem como manter a própria estrutura estatal em funcionamento".

Esse também é o posicionamento de Nabais (2011, p. 21), para quem a existência de um sistema fiscal é imprescindível para a concretização de direitos, visto que esses "implicam a cooperação social e a responsabilidade individual. Daí decorre que a melhor abordagem para os direitos seja vê-los como liberdades privadas com custos públicos".

Dessa forma, afirmar que o Estado tem na arrecadação de tributos sua principal fonte de financiamento, "significa reconhecer que um dos principais deveres inerentes à cidadania consiste em pagar tributos" (BUFFON; MATOS, 2015, p.143).

Todavia, apesar da importância da tributação para o desenvolvimento das funções estatais, a Constituição Federal, em seus artigos 150 a 152, estabeleceu limites ao poder de tributar do Estado e instituiu importantes princípios de direito tributário, dentre os quais se destacam: o da legalidade, o da igualdade, o da anterioridade, o da vedação aos efeitos do confisco e da não limitação ao tráfego de pessoas ou bens, a fim de assegurar garantias aos contribuintes (BRASIL, 1988).

Ademais disso, a Carta de 1988, em seu artigo 170, ao tratar da ordem econômica e financeira, positivou que a república tem por finalidade assegurar a todos uma existência digna, de acordo com ditames da justiça social e, entre os vários princípios, a redução das desigualdades regionais e sociais, com fundamento da valorização do trabalho humano e na livre iniciativa. Assim sendo, verifica-se que Constituição, ao estabelecer como um dos princípios da ordem econômica, no inciso VII ${ }^{2}$, do artigo 170, a redução das desigualdades

2 Art. 170. A ordem econômica, fundada na valorização do trabalho humano e na livre iniciativa, tem por fim assegurar a todos existência digna, conforme os ditames da justiça social, observados os seguintes princípios:

VII - redução das desigualdades regionais e sociais. 
sociais e regionais, objetivou, com isso, garantir a efetividade de um dos objetivos fundamentais da república ${ }^{3}$ (BRASIL, 1988).

Não obstante, da leitura do $\S 1^{\circ}$ do artigo 145 da Constituição, constatase, ainda, a preocupação do constituinte em adequar a tributação ao princípio da capacidade contributiva, o qual pode ser visto como "um desdobramento da ideia de igualdade" e como um importante "instrumento que deve ser utilizado na busca de uma tributação adequada", através de um de seus aliados, qual seja: o princípio da progressividade (BUFFON; MATOS, 2015, p. 139).

Diante dos apontamentos acima, pode-se afirmar que a Constituição conferiu aos tributos, através dos princípios da capacidade contributiva e da progressividade, um importante papel na concretização dos objetivos do Estado Democrático de Direito.

\section{NOÇÕES SOBRE OS PRINCÍPIOS DA CAPACIDADE CONTRIBUTIVA E DA PROGRESSIVIDADE}

O termo "princípio", que, etimologicamente, possui sua origem nas palavras latinas pricipium, principii, traduz a ideia de começo, origem, alicerce. Na filosofia, esse termo foi utilizado, por Platão, "no sentido de fundamento do raciocínio", por Aristóteles, como "premissa maior de uma demonstração" e por Kant, como "preposição geral que pode servir como premissa maior" (CARRAZZA, 2002, p. 30-31).

No âmbito do Direito, o termo o "princípio" é utilizado para indicar normas que fixam importantes critérios objetivos, bem como para dar significado às regras e aos valores (CARVALHO, 2008).

Nessa perspectiva, Mello (2008, p. 942-943) define princípio como mandamento, alicerce de um sistema, na medida em que "se irradia sobre diferentes normas compondo-lhe o espírito e servindo de critério para sua exata compreensão e inteligência exatamente por definir a lógica e a racionalidade do sistema normativo, no que lhe confere a tônica e lhe dá sentido harmônico".

Sarmento, de forma semelhante, (2002, p. 42) aduz que os princípios são "as traves-mestras do sistema jurídico, irradiando seus efeitos sobre diferentes normas e servindo de balizamento para a interpretação e a integração de todo o setor do ordenamento".

Nessa mesma linha, Buffon (2003, p.21) entende que os princípios devem ser compreendidos "como verdadeiros alicerces do ordenamento jurídico, que

3 Art. $3^{\circ}$ Constituem objetivos fundamentais da República Federativa do Brasil:

I - construir uma sociedade livre, justa e solidária;

II - garantir o desenvolvimento nacional;

III - erradicar a pobreza e a marginalização e reduzir as desigualdades sociais e regionais;

IV - promover o bem de todos, sem preconceitos de origem, raça, sexo, cor, idade e quaisquer outras formas de discriminação 
subordinam as demais normas, porquanto o sentido destas deve ser construído no mesmo sentido daqueles, estejam explícitos ou implícitos".

Dentro dessa perspectiva, dos princípios como a base, o "fio condutor" do ordenamento, entende-se que as normas no âmbito do direito tributário devem estar de acordo com os princípios da capacidade contributiva e da progressividade. Isso porque, se assim for, invariavelmente, "[...] a tributação contribuirá, a seu modo, para a máxima proteção e eficácia das garantias constitucionais" (BUFFON; MATOS, 2015, p. 140).

No tange ao princípio da capacidade contributiva, esse possui origem na ideia de igualdade e justiça, já que "surge como forma de mediar a vontade arrecadatória do Estado, evitando, assim, que este onerasse em demasia o contribuinte" (DUTRA, 2010, p. 62)

De acordo com a autora (2010), há registro da aplicação do referido princípio, em que pese não da forma como hoje é concebida, já na época de Sólon, em Atenas, onde a cobrança de impostos se baseava em quatro categorias de contribuintes, as quais levavam em consideração o grau de recursos que cada um dispunha.

No que se refere à positivação constitucional do princípio da capacidade contributiva, a primeira constituição a inseri-lo em seu texto, de forma explícita, foi a francesa de 1791, que exerceu grande influencia nas constituições romana de 1798, espanhola de 1812 e portuguesa de 1822 e 1938 (DUTRA, 2010).

No direito brasileiro, a primeira menção ao aludido princípio pode ser encontrada na Constituição de 1824, apesar desse, de modo expresso, somente ser contemplado na Constituição de 1946, a qual previa em seu artigo 202 que "os tributos terão caráter pessoal, sempre que isso for possível, e serão graduados conforme a capacidade econômica do contribuinte" (CONTI, 1997, p. 39).

Todavia, foi somente com a promulgação da Constituição Federal de 1988, a qual, conforme já referido, instituiu no Brasil um Estado Democrático de Direito, que o princípio da capacidade contributiva, além de encontrar previsão constitucional expressa e ser visto como densificador do princípio da igualdade, passou a "[...] ser entendido como corolário da justiça fiscal, visto que sua observância implica que a carga tributária seja repartida de acordo com a possibilidade de cada indivíduo de suportá-la" (BUFFON, 2009, p. 178).

$\mathrm{O}$ referido princípio encontra-se disposto no artigo $145, \S 1^{\circ}$, da Constituição Federal", cuja redação se destaca no seguinte ponto: "sempre que

4 Art. $145 \S 1^{\circ}$ : Sempre que possível, os impostos terão caráter pessoal e serão graduados segundo a capacidade econômica do contribuinte, facultado à administração tributária, especialmente para conferir efetividade a esses objetivos, identificar, respeitados os direitos individuais e nos termos da lei, o patrimônio, os rendimentos e as atividades econômicas do contribuinte 
possível os impostos terão caráter pessoal e serão graduados segundo a capacidade econômica do contribuinte" (BRASIL, 1988).

Aqui, cumpre frisar que apesar da utilização da expressão sempre que possível, na primeira parte do referido texto constitucional, essa, de maneira alguma, "pode ser entendida no sentido de que, apenas, ocasionalmente, os impostos, ditos pessoais [...] poderiam estar adstritos à efetiva capacidade econômica do sujeito passivo", pois tal afirmação restringiria, por exemplo, a aplicação do $\S 1^{\circ}$ do artigo 145 ao imposto de renda das pessoas físicas (BUFFON, 2009, p. 171).

A respeito do tema, Tipke e Yamashita (2002, p. 27) entendem que "se com o trecho introdutório "sempre que possível" o constituinte queria dizer que basta criar um princípio meramente programático, não vinculante para o legislador, este passaria ao largo das necessidades do Estado de Direito".

Com base nisso, verifica-se que não é possível uma interpretação taxativa do disposto no $\S 1^{\circ}$ do artigo 145 da Constituição, pois a "política fiscal tem de ser política de justiça, e não mera política de interesses", ou seja, a aplicação do princípio da capacidade contributiva, por ser decorrência lógica do princípio da igualdade, não pode ficar "a mercê" dos interesses e conveniências do legislador, pois, se assim fosse, as necessidades do Estado de Direito jamais seriam atendidas (TIPKE; YAMASHITA, 2002, p. 28).

Nessa linha, Nabais (2004, p.443) entende que "o princípio da igualdade de tributação, assente no princípio da capacidade contributiva, diz-nos que as pessoas devem tributadas em conformidade com a respectiva capacidade contributiva", ou seja, aqueles que não possuem capacidade devem ser excluídos da tributação, já aqueles detentores de igual capacidade deverão sofrer a mesma incidência tributária, de modo a se garantir a igualdade horizontal e, por fim, aqueles com capacidades diferentes, seja em termos quantitativos ou qualitativos, devem ser tributados de modo desigual, a fim de se assegurar a igualdade vertical.

Ainda, a esse respeito, Amaro (2012, p. 160) leciona que "hão de ser tratados, pois, com igualdade aqueles que tiverem igual capacidade contributiva, e com desigualdade os que revelem riquezas diferentes e, portanto, diferentes capacidades de contribuir".

Isso porque, o princípio da capacidade contributiva, a luz dos objetivos fundamentais da República, não impõe que "todos devam pagar igualmente o mesmo tributo", mas, sim, que "carga tributária do indivíduo seja mensurada segunda sua renda" (TIPKE; YAMASHITA, 2002, p.44).

Além do mais, outro não poderia ser o raciocínio, pois se o Estado objetiva reduzir as desigualdades sociais, "[...] não poderiam as pessoas ser tributadas de outra forma, porque, inegavelmente, aquelas pessoas mais abastadas podem (e devem!) contribuir de maneira mais acentuada com as despesas em prol dos demais cidadãos sem capacidade" (BUFFON; MATOS, 2015, p. 156). 
Contudo, cumpre advertir que somente se pode falar em capacidade contributiva a partir do momento em que as necessidades básicas do indivíduo encontram-se asseguradas, pois "o Estado não pode, como Estado Tributário, subtrair o que, como Estado Social, deve devolver" (TIPKE; YAMASHITA, 2002, p.34).

De semelhante modo, a tributação não pode ser utilizada como instrumento limitador de direitos, pois "exigindo-se tributo além da capacidade contributiva, se está diante de inegável confisco tributário" (CASTILHO, 2002, p. 93).

Nesse ínterim, objetivando-se tanto a manutenção do mínimo existencial quanto uma tributação que não atinja níveis de confisco, que a progressividade tributária, fundada na capacidade contributiva, pode ser entendida como um princípio densificador da igualdade (COSTA, 2003).

Isso porque, "o principio da progressividade tributária implica, dentro de uma concepção tradicional, a elevação da exigência de tributos à medida que cresce a capacidade de contribuir com a coletividade", o que pode ser operacionalizado "pela incidência de alíquotas maiores à medida que a base imponível seja maior", (BUFFON, 2003, p. 81).

Esse também é o entendimento de Torres (2005, p. 314), para quem o princípio da progressividade impõe que a tributação seja realizada "[...] por alíquotas ascendentes na proporção em que se avolume a base de cálculo. Quanto maior a base de cálculo, tanto maior deverá ser também a alíquota, produzindo resultado crescente".

Amaro (2012, p.166), por sua vez, compreende que "a progressividade não é uma decorrência necessária da capacidade contributiva, mas sim um refinamento desse postulado".

De semelhante modo, Tipke e Yamashita (2002, p. 35), afirmam que apesar do princípio da capacidade contributiva não exigir a progressividade de alíquotas, "[...] sua admissibilidade resulta do princípio do Estado Social".

A respeito do tema, Buffon (2009, p.189) doutrina que a progressividade, no Brasil, encontra seu fundamento no próprio modelo de Estado Democrático de Direito, o qual exige que o sistema tributário esteja "[...] fundado no princípio da capacidade contributiva, o que, em regra, implica imposição fiscal progressiva".

Aqui, faz-se imperioso destacar que existem duas espécies de progressividade, quais sejam: a fiscal e a extrafiscal. A primeira, objetiva o "aumento da exigência fiscal na medida em que cresce a capacidade de cooperar com a sociedade, por meio de alíquotas maiores quanto maior for a base de cálculo". A segunda "[...] é representada pelo aumento de alíquotas independentemente da capacidade contributiva", pois visa objetiva estimular ou desestimular condutas (BUFFON; MATOS, 2015, p. 170). 
Em assim sendo, quando se objetiva tributar "[...] através de alíquotas proporcionalmente maiores aquela parcela de contribuintes que possuem uma maior capacidade de contribuir [...]", o Estado deve-se valer da progressividade fiscal (BUFFON, 2003, p. 84).

A despeito disso, o autor (2003, p. 92) adverte que a tributação progressiva não pode ser confundida com a tributação proporcional, pois nessa "ocorre a incidência de alíquotas fixas, não obstante a base imponível seja diferenciada", diferentemente do que ocorre naquela.

Objetivando elucidar as diferenças entre a tributação proporcional e a progressiva, Amaro (2012, p. 166) aduz que "a proporcionalidade implica que riquezas maiores gerem impostos proporcionalmente maiores (na razão direta do aumento da riqueza). Já a progressividade faz com que a alíquota para as fatias mais altas de riqueza seja maior".

Feita essa distinção, pode-se compreender que “[...] a tributação progressiva é um instrumento mais efetivo do que a tributação proporcional, com vistas a concretizar o princípio da capacidade contributiva e, via de consequência atingir a igualdade material" (BUFFON, 2003, p. 93).

Com base no exposto, verifica-se que os princípios da capacidade contributiva e da progressividade podem ser entendidos como um importante instrumento na efetiva concretização da igualdade tributária e, consequentemente, da justiça fiscal.

\section{OS PRINCÍPIOS DA CAPACIDADE CONTRIBUTIVA E DA PROGRESSIVIDADE COMO CRITÉRIO PARA UMA TRIBUTAÇÃO JUSTA}

A tributação, especialmente, a progressiva, frente aos fins de um Estado Democrático de Direito, somada as diretrizes do sistema tributário e do Estado fiscal social, é um importante instrumento na busca pela realização dos direitos fundamentais, na medida em que, observada a capacidade contributiva, se passa a "exigir de que cada cidadão aquilo que ele tem condições de entregar para colaborar com os demais, exercendo assim seu dever/direito de cidadania" (BUFFON; MATOS, 2015, p. 143).

Ademais disso, também, deve ser levado em consideração que o critério da progressividade, que é "consectário natural dos princípios da igualdade e da capacidade contributiva", constitui-se como um grande aliado para que haja uma melhor redistribuição de renda que, por via de consequência, "auxilia a concretização da igualdade material (concreta e substancial), consagrada em nosso Estado Democrático de Direito, plasmado pela Constituição de 1988" (CARRAZZA, 2009, p. 72-73).

Isso porque, conforme visto anteriormente, pagar tributos muito mais do que um sacrifício é um dever e "[...] uma contribuição necessária para que o 
Estado possa cumprir suas tarefas no interesse do proveitoso convívio de todos os cidadãos" (TIPKE; YAMASHITA, 2002, p. 15).

Em razão disso, como ressaltam os referidos autores (2002), a tributação não possui influência, somente, na relação do Estado com os cidadãos, pois ela afeta, também, a relação dos cidadãos uns com os outros. Daí a importância de se constituir um direito justo, ou melhor, um direito tributário justo.

A respeito do tema, Tipke (2012, p.13) ensina que em um Estado Democrático de Direito, na medida do possível, "[...] tudo deve ocorrer com justiça. Essa é a mais alta exigência, que se pode fazer perante ele. Essa exigência não pode em sua essência ser anulada ou deslocada por outras exigências. Daí partem também as constituições que [...] invocam a Justiça ou a Justiça Tributária".

Contudo, Buffon e Matos (2015) advertem que uma exigência justa de tributos deve nortear tanto a atividade tributária no âmbito do Poder Legislativo quanto do Executivo, através da administração fiscal, porquanto "não basta que o imposto seja legal, pois mister se faz que, acima de tudo, o tributo seja justo, tendo por causa jurídica uma situação fática representativa da capacidade contributiva" (MORAES, 1999, p. 118).

Nessa linha, Tipke (2012, p.16) entende que, muito mais do que pela igualdade perante a lei, no direito tributário, a justiça é garantida "pela igualdade na distribuição da carga tributária (Gleichbelastung)", que pode ser concretizada com a observância a princípios.

Assim sendo, de modo inverso, pode-se dizer que a não observância de princípios torna uma sociedade menos igualitária, justa e solidária, pois é através desses que se confere tratamento isonômico a todos os cidadãos que se encontram em uma mesma condição (TIPKE; YAMASHITA, 2002).

Apesar disso, os autores (2002, p. 20) referem que a existência de princípios é "apenas o pressuposto básico para a justiça. Ela cria apenas justiça formal", ou seja, mesmo que todos sejam tratados, formalmente, de modo igual, podem não ser tratados de maneira justa, caso o princípio ou o critério não seja justo. Portanto, não é a justiça formal que exige orientação por princípios, sim, a material, que, no direito tributário, deve ser orientada pelo princípio da capacidade contributiva.

Em vista disso, Ribeiro (2009, p. 210) salienta que "[...] o ideal da Justiça Fiscal, hoje, se realiza na investigação de quanto cada cidadão pode contribuir com as despesas públicas, à luz dos valores e princípios reatores do Estado Democrático e Social", ou seja, para que haja justiça, o Estado, ao tributar, deve respeitar a capacidade contributiva de cada sujeito passivo, sob pena de "[...] as prestações estatais serem realizadas à custa de parcelas indispensáveis à vida digna do homem".

Deste modo, verifica-se que "o princípio da capacidade contributiva não investiga o que o Estado e comunidade podem fazer pelo cidadão isolado, 
senão o que o cidadão isolado, com base na sua capacidade contributiva, pode fazer por seu Estado e sua comunidade", pois um tratamento fiscal justo requer que seja respeitada a capacidade contributiva dos cidadãos já no momento em que se exige o pagamento de tributos (TIPKE, 1998, p. 64).

Esse, também, é o entendimento de Caliendo (2009) para quem o princípio da capacidade contributiva deve fundamentar exigência do dever de pagar tributos, pois, do contrário, esses seriam instituídos de modo arbitrário ou como forma de manifestação do poder estatal.

Amaro (2012, p. 164), por seu turno, assevera que o princípio da capacidade contributiva requer que a justiça da incidência tributária seja aferida em cada situação isoladamente, assegurando-se, assim, "um dos aspectos da igualdade, que é o tratamento desigual para os desiguais".

Nessa linha, Tipke (1988, p. 64) sustenta que o princípio da capacidade contributiva, que é reconhecido universalmente, seja de modo expresso pelas constituições, seja como uma derivação do princípio da igualdade, "é o único princípio justo no âmbito tributário; é, portanto, o único parâmetro justo de comparação para a aplicação do princípio da igualdade".

Não obstante isso, conforme anteriormente exposto, entende-se que "o princípio segundo o qual a tributação deve estar de acordo com a capacidade econômica do contribuinte pode ser concretizado através da tributação progressiva", pois essa (progressividade) fundada naquela (capacidade contributiva) deve ser compreendida como critério para uma exigência justa de tributos (BUFFON, 2003, p. 92).

Dessa forma, segundo o autor (2003), a progressividade tributária pode ser vista como um meio através do qual o princípio da igualdade é densificado, ou melhor, como um importante instrumento colocado à disposição do Estado, a fim de que esse atinja aos objetivos fundamentais da República, sobretudo, os preconizados no artigo $3^{\circ}$ da Constituição Federal.

Nesse ínterim, Ribeiro (2009) salienta que, em uma sociedade na qual as desigualdades sociais são tão evidentes, como ocorre na brasileira, o princípio da capacidade contributiva encontra na progressividade o mecanismo mais eficaz para sua realização.

Conforme Buffon e Matos (2015, p. 171) “[...] a progressividade se traduz em um critério econômico pelo qual se aplica maior carga tributária àquele que possui melhores condições econômicas para suportar os custos do Estado", ou seja, se confere tratamento desigual àqueles em situação desigual, a fim de que as desigualdades sejam reduzidas.

Em vista disso, entende-se que, quando um Estado Democrático de Direto busca no princípio da igualdade o fundamento para uma tributação progressiva que esteja em consonância com capacidade contributiva dos cidadãos, ele deve almejar não, apenas, a igualdade formal, mas, a material 
ou substancial, pois somente com a solidificação dessa é que se alcançará uma efetiva justiça fiscal (TIPKE; YAMASHITA, 2002).

A esse respeito, Buffon (2003, p. 85) entende que se não for possível a concretização da igualdade substancial, faz-se, pelo menos, necessária a diminuição das desigualdades entre os cidadãos, pois, se assim não for, "[...] como justificar a legitimidade de um Estado que não busca, de fato, atingir os objetivos que estão formalmente postos como razão de sua existência?"

Diante de tudo o que foi exposto, acredita-se que a observância e a materialização dos princípios da capacidade contributiva e da progressividade devem ser buscadas pela tributação, a fim de que essa seja justa e, via de consequência, seja uma ferramenta eficaz na efetivação dos objetivos da República Federativa do Brasil, os quais são os tentáculos de sustentação do próprio Estado.

\section{CONCLUSÃO}

A partir da análise realizada, pode-se constatar que a tributação, especialmente a fundada em princípios, é um importante instrumento colocado a disposição do Estado, a fim de que esse possa cumprir com suas finalidades, dentre as quais se destaca a redução das desigualdades sociais.

Contudo, percebeu-se que apesar da Constituição Federal fornecer o norte para que o Estado Democrático de Direito, que foi erigido como vistas a incorporar e a superar os modelos que o antecederam, direcionando as suas ações no sentido de construir uma sociedade mais livre, justa e igualitária, tal função transformadora da realidade social vem sendo negligenciada.

Isso porque, verificou-se que, atualmente, a tributação, por não ser adequadamente exigida, tem sido uma ferramenta indutora de desigualdades sociais, na medida em que o Estado, ao instituir ou majorar tributos, não tem observado se as alíquotas aplicadas estão em consonância com real e efetiva capacidade dos contribuintes.

Em vista disso, para que a tributação cumpra com sua função redistributiva, pela via da arrecadação, observou-se a necessidade de adequála aos princípios da capacidade contributiva e da progressiva, pois é por meio delas que a igualdade tributária material e, consequentemente, a justiça fiscal podem vir a ser concretizadas no Brasil.

Nessa linha, constatou-se, também, que o Estado deve, desde o momento da arrecadação, primar para que os princípios balizadores da justiça fiscal sejam observados, a fim de que a tributação não tenha caráter confiscatório e, tão pouco, atinja o mínimo vital.

Por fim, conclui-se que o sistema tributário pode, desde que observados os princípios a ele inerentes, os quais já foram delimitados e definidos pela 
Constituição Federal, por meio de uma efetiva justiça fiscal, contribuir para que seja, de fato, solidificada a justiça social no Brasil.

\section{REFERÊNCIAS}

BRASIL. Constituição (1988). Constituição da República Federativa do

Brasil. Disponível em: <http://www.planalto.gov.br/ccivil_03/constituicao/ constitui\%C3\%A7ao.htm>. Acesso em: 21 nov. 2018.

BOLZAN DE MORAIS, Jose Luis. Revistando o Estado!: da crise conceitual à institucional (constitucional). In: Anuário do Programa de Pós Graduação em DireitoMestrado/Doutorado. São Leopoldo: Unisinos, 2000

BUFFON, Marciano; MATOS, Mateus Bassani de. Tributação no Brasil no século XXI: uma abordagem hermenêutica crítica. Porto Alegre: Livraria do Advogado Editora, 2015.

Tributação e dignidade da pessoa humana: entre os direitos e deveres fundamentais. Porto Alegre: Livraria do Advogado Editora, 2009.

. O princípio da progressividade tributária na Constituição Federal de 1988. São Paulo: Memória Jurídica Editora, 2003

CALIENDO, Paulo. Direito tributário: três modos de pensar a tributação: elementos para uma teoria sistemática do direito tributário. Porto Alegre:Livraria do Advogado Editora, 2009.

CANOTILHO, Jose Joaquim Gomes. Direito Constitucional e teoria da Constituição. 6. ed. Coimbra: Almedina, 2002.

CARRAZZA, Roque Antonio. Imposto sobre a renda (perfil constitucional e temas específicos). 3. ed. São Paulo: Malheiros, 2009

CARVALHO, Paulo de Barros. Curso de direito tributário. 20. ed. rev. e atual. São Paulo: Saraiva, 2008.

CASTILHO, Paulo Cesar Baria de. Confisco tributário. São Paulo: Revista dos Tribunais, 2002.

CONTI, José Maurício. Princípio Tributários da Capacidade contributiva e da progressividade. São Paulo: Dialética, 1997.

COSTA, Regina Helena. Principio da capacidade contributiva. 3. ed. São Paulo: Malheiros, 2003.

DALLARI, Dalmo de Abreu. Elementos de teoria geral do Estado. 22 .ed. São Paulo: Saraiva, 2001. 
DUTRA, Micaela Dominguez. Capacidade contributiva: análise dos direitos humanos e fundamentais. São Paulo: Saraiva, 2010.

MELLO, Celso Antônio Bandeira de. Curso de direito administrativo. 25. ed. São Paulo: Malheiros, 2008.

MORAES, Bernardo Ribeiro de. Compêndio de Direito Tributário. 3.ed. Rio de Janeiro: Forense, 1999.

NABAIS, José Casalta. O Dever fundamental de pagar impostos: contributo para a compreensão constitucional do estado fiscal contemporâneo. Coimbra: Almedina, 2004

. Por um estado fiscal suportável- Estudos de Direito Fiscal. Coimbra:

Almedina, 2011.

NOGUEIRA, Alberto. Direito Constitucional das Liberdades Públicas. Rio de Janeiro: Renovar, 2003.

RIBEIRO, Ricardo Lodi. Temas de Direito Constitucional Tributário. Rio de Janeiro: Editora Lumen Juris, 2009.

SARMENTO, Daniel. A ponderação de Interesses na Constituição Federal. Rio de Janeiro: Editora Lumen Juris, 2002.

STRECK. Lenio Luiz. Jurisdição Constitucional e Hermenêutica: Uma nova crítica do Direito. Porto Alegre: Livraria do Advogado, 2002.

TORRES, Ricardo Lobo. Curso de direito financeiro e tributário. 18 ed. Rio de Janeiro: Renovar, 2011.

Tratado de direito constitucional financeiro e tributário. Rio de Janeiro:

Renovar, 2005. v.2.

TIPKE, Klaus; YAMASHITA, Douglas. Justiça Fiscal e Princípio da capacidade contributiva. São Paulo: Malheiros, 2002.

. Moral tributária do estado e dos contribuintes. Tradução Luiz Dória

Furquim. Porto Alegre: Sérgio Antonio Fabris Ed., 2012. 